\title{
The behaviour of water-repellent mortars with regards to salt crystallization: from mortar specimens to masonry/ render systems
}

\author{
Laura Falchi · Elisabetta Zendri · Eleonora Capovilla $\cdot$ Piercarlo Romagnoni $\cdot$ Massimiliano De Bei
}

Received: 19 January 2016/Accepted: 18 May 2016/Published online: 22 August 2016

(C) RILEM 2016

\begin{abstract}
This study is specifically concerned with the behaviour of water-repellent mortar specimens and masonry-render systems upon the penetration and crystallization of salt solutions. Portland limestone cement, natural hydraulic lime and Pozzolana lime were admixed with siloxanes and calcium stearates to obtain water-repellent mortars and renders. In order to select the most suitable water-repellent mixtures in the presence of salt solutions, investigations were carried out upon mono-material mortar specimens and macrosamples (masonry-render systems). Alongside pore structure characterization, the behaviour in connection with water and mechanical properties were determined. In addition, a non-invasive diagnostic methodology is proposed for the study of masonry macrosamples, including thermal imaging, water absorption at low pressure, and sclerometric measurments. The results revealed the difference between the behaviour of the mortar specimens in comparison to the masonry/render systems. Among the mortar specimens, Portland limestone cement mixtures
\end{abstract}

L. Falchi $(\bowtie) \cdot$ E. Zendri · E. Capovilla

Department of Environmental Sciences, Informatics and Statistics, Ca' Foscari University of Venice, Scientific Campus of Via Torino 155/eta, 30170 Venice, Italy e-mail: Laura.falchi@unive.it

P. Romagnoni · M. De Bei

FisTec Lab, Department of Design and Planning in Complex Environments, IUAV University, via Torino 153/A, 30170 Venice, Italy demonstrated better resistance to salt crystallization, whilst those of natural hydraulic lime showed a longer service life, when applied as renders to masonry subjected to rising damp of sodium sulphate solution.

Keywords Water-repellent mortars $\cdot$ Salt resistance $\cdot$ Sodium sulphate $\cdot$ Masonry-render system $\cdot$ Siloxanes $\cdot$ Stearates

\section{Introduction}

The presence of moisture and salt within the mortars and masonry structures, causes severe decay, such as spalling, cracking, detachment and efflorescence [1-6]. Amongst the systems proposed to protect historical masonries the use of adequate render layers is one of the most diffuse [7-9]. Renders and plasters not only act as a building's protective shell against external water sources (e.g. rain, bad drainage conditions, etc.), but also play a central role in regulating the movement of moisture and salt within the walls $[7,10]$. The classification of renders in relation to water-transport behaviour is still controversial on the market: ready-mix renders working according to different mechanisms have similar names or viceversa. The renders can be classified within the following categories [11, 12, 13]: accumulating renders, transporting renders, salt blocking plasters, moisture sealing plasters. Accumulating renders are used as 
sacrificial layers allowing the salts to crystallise within the mortar thanks to an evaporation front located within the render. The front location is influenced by fast evaporation causing front recede within the render bulk or by multi-layer render (a water-repellent external layer block the solution transfer, water evaporate and the salts are deposited at the layers' interfaces). Usually, accumulating renders deteriorate quickly and must be substituted after few years, but guarantee lower damage to the underlying masonry. Tansporting plasters allow transport of water and salt outside the wall. Often they are completely wettable to favour the solution transfer and consist of limited protection against meteoric precipitation. Salt blocking and moisture sealing plaster cause salt precipitation within the masonry or moisture retention, respectively. Moisture sealing plasters cause recrudescence of rising damp phenomena and raising of water level.

Water-repellent renders, obtained by using waterrepellent admixtures, prove particularly promising in the protection against meteoric precipitation, by avoiding a fast water entrance and by allowing high water vapour permeability [8, 9, 14]. However, in the presence of continuous solution flux, i.e. rising damp of salt solutions, it is essential to examine water-repellent systems closely, taking into account their capability of transporting salt solutions, stiffness and adhesion to the masonry. Moreover, when dealing with historical masonries, particular attention should be paid when selecting compatible repair materials, preferring the degradation of the repair material over the degradation of the original substrate $[12,15,16]$.

Regarding the commercial renders, few physical parameters, calculated according to normalised tests on small, mono-material, laboratory specimens, are usually given. These normalised tests have been developed in terms of reproducibility and sustainability from a commercial/economic point of view. Whereas, complex and time-consuming tests on macro samples/scale models are not always carried out. However, it is an already established fact that scale models, due to their size and complexity, constitute an important intermediate level between the laboratory and field application. A large literature regarding the importance of scale models and of on-site investigation have been produced [17-21].

\subsection{Survey's objectives and methodology}

Throughout this study, the characterization of hardened mortar specimens before and after salt crystallization tests was followed by the application of mortar mixtures as renders upon brick masonry models, subjected to capillary rise of salt solutions. By adopting this "micro-to-the-macro" approach, the properties of both the mortars themselves and of more complex masonry-render systems were considered, in order to evaluate the compatibility and suitability of mortar mixtures as restoration renders. This research aims to contribute to existing literature $[19,20,22,23]$, in order to raise awareness of the problems associated with testing methods, focusing particularly on tests of single materials versus tests of more complex structures.

Three binders (a Portland limestone cement, a natural hydraulic lime, a mixture of Pozzolana and lime) and two water-repellent admixtures (calcium stearate and siloxane in powder form), were selected in preparation of nine different mortar mixtures in order to: (i) propose renders that are compatible with historical structures; (ii) evaluate the effects of commonly used admixtures on render properties; (iii) give a wide overview of systems with different hygric behaviour tested in the same experimental conditions [15, 24, 25]. In particular, the choice of natural hydraulic lime and pozzolana-lime allow higher flexibility, ductility, lower strength and stiffness in comparison to cement render, thus a better compatibility with historical masonries is often observed [26]. On account of cement mortar's noncompatible characteristics, Portland limestone cement was chosen instead, given the extensive use of cement renders within past restoration interventions.

Immersion cycles, in saturated sodium sulphate solutions, were carried out in order to test the monomaterial specimen's resistance to salt crystallization, whilst wall-render macro samples were subjected to rising damp of sodium sulphate solution to evaluate a complex wall-render system. The experimental conditions were chosen in order propose an accelerated test that simulate historical masonries constituted of handmade clay-fired bricks subjected to an aggressive environment $[4,27]$.

The mortar's structure over time, the mechanical and hygric behaviours, the salt distribution within the mortars, were each analysed before and after the 
exposures. Particular attention was paid in the selection of non-invasive characterization for the study of the wall-render system: portable and non-destructive techniques, suitable for an in situ use, were applied [28]. Photographic campaigns of the masonries in visible light and by thermal imaging were followed by non-destructive sclerometric measurements and water absorption measurements with a pipe apparatus. Owing to the non-invasive campaign indications, very few significant samples were needed to be collected for destructive porosity determination.

\section{Materials and methods}

\subsection{Starting materials and mortar mixtures}

Table 1 summarizes the composition and proportion of the mortar mixtures, moreover the brick and rough render used to build the macro-sample are described.

A Portland limestone cement CEMII B/L $[24,29,30]$ (by CementiRossi ${ }^{\circledR}$ with a $30 \%$ of
$\mathrm{CaCO}_{3}$ ) and a local silicate-carbonate sand, commonly found within the Venetian area/or region (size fraction of $0 / 1.5$ ), were both used to prepare limestone cement mortars.

The dry-mix mortar VIMAK BIO (by Villaga $\mathrm{SpA}^{\circledR}$ ), made with a natural hydraulic lime NHL 3.5 and carbonate aggregates (size fraction 0/1.8), was used to prepare natural hydraulic lime mortars.

Pozzolana-lime mortars were obtained by mixing $\mathrm{S} \& \mathrm{~B} \mu$-silica ${ }^{\circledR}$, a greek ultrafine aluminosilicate poz-

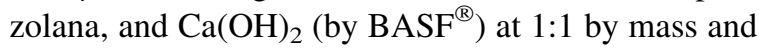
adding a standard sand with a size fraction of $0 / 2$ [14].

The selected water-repellent admixtures, a triethoxysiloxane supported on amorphous silica powder (Sitren P750, by Evonik) or calcium stearate (Sigma Aldrich $^{\circledR}$ ), were added at $1 \%$ by dry mass in the different mortar mixtures. Mortar mixtures without water-repellent admixtures were used as "reference mortars" for each binder system. Preparation involved mixing the components in a planetary mixer at low speed $(145 \pm 10 \mathrm{rpm})$, subsequently, water was poured over the dry components and mixed for a

Table 1 Mix design of mortar mixtures

\begin{tabular}{|c|c|c|c|c|c|c|}
\hline \multirow[t]{2}{*}{ Mix name } & \multicolumn{6}{|c|}{ Mortar mixture composition } \\
\hline & Binder & Aggregate & $\begin{array}{l}\text { b/a by mass (by } \\
\text { volume) }\end{array}$ & $\mathrm{w} / \mathrm{b}$ & Water-repellent admixture & $\begin{array}{l}\text { WR \% by } \\
\text { mass }\end{array}$ \\
\hline $\mathrm{CM} ; \mathrm{CR}$ & CEMII/B-L & $\begin{array}{l}\text { Silicatic and carbonatic } \\
\text { sand }(0 / 1.5)\end{array}$ & $1: 4.1(1: 3)$ & 0.69 & None & - \\
\hline $\begin{array}{l}\text { CM750; } \\
\text { CR750 }\end{array}$ & CEMII/B-L & $\begin{array}{l}\text { Silicatic and carbonatic } \\
\text { sand }(0 / 1.5)\end{array}$ & $1: 4.1(1: 3)$ & 0.69 & $\begin{array}{l}\text { Triethoxysiloxanes on } \\
\text { amorphous silica powder }\end{array}$ & 1 \\
\hline $\begin{array}{l}\text { CMcast; } \\
\text { CRcast }\end{array}$ & CEMII/B-L & $\begin{array}{l}\text { Silicatic and carbonatic } \\
\text { sand }(0 / 1.5)\end{array}$ & $1: 4.1(1: 3)$ & 0.69 & Calcium stearates & 1 \\
\hline NM; NR & NHL3,5 & Carbonate sand $(0 / 1.2)$ & $1: 5.1(1: 3)$ & 0.50 & None & - \\
\hline $\begin{array}{l}\text { NM750; } \\
\text { NR750 }\end{array}$ & NHL3,5 & Carbonate sand (0/1.2) & $1: 5.1(1: 3)$ & 0.50 & $\begin{array}{l}\text { Triethoxysiloxanes on } \\
\text { amorphous silica powder }\end{array}$ & 1 \\
\hline $\begin{array}{l}\text { NMcast; } \\
\text { NRcast }\end{array}$ & NHL3,5 & Carbonate sand (0/1.2) & $1: 5.1(1: 3)$ & 0.50 & Calcium stearate & 1 \\
\hline PM; PR & Lime + pozzolan & Siliceous sand $(0 / 2)$ & $1: 7(1: 3)$ & 1.25 & None & - \\
\hline $\begin{array}{l}\text { PM750; } \\
\text { PR750 }\end{array}$ & Lime + pozzolan & Siliceous sand $(0 / 2)$ & $1: 7(1: 3)$ & 1.29 & $\begin{array}{l}\text { Triethoxysiloxanes on } \\
\text { amorphous silica powder }\end{array}$ & 1 \\
\hline $\begin{array}{l}\text { PMcast; } \\
\text { PRcast }\end{array}$ & Lime + pozzolan & Siliceous sand $(0 / 2)$ & $1: 7(1: 3)$ & 1.29 & Calcium stearate & 1 \\
\hline Brick & \multicolumn{6}{|c|}{ Full fired clay bricks } \\
\hline $\begin{array}{l}\text { Wall } \\
\text { render }\end{array}$ & \multicolumn{6}{|c|}{$\begin{array}{l}\text { Dry-mix lime-cement rough render coat (binder: 1:1 Portland cement/slaked lime; with aggregate containing quartz, } \\
\text { silicates and limestone) }\end{array}$} \\
\hline
\end{tabular}

Mix name ( $M$ mortar, $R$ render applied on walls); binder; aggregate; binder-aggregate ratio (b/a); water-binder ratio (w/b); water repellent admixture type and percentage (WR \%). The table reports also the description of the bricks and the mortar used as grout and rough coat (WR wall render) for wall macro-sample building 
further $3 \mathrm{~min}(285 \pm 10 \mathrm{rpm})$. The mixtures were used to obtain mono-material specimens or were rather applied as renders on models of brick walls (Table 1), as described in the following paragraphs.

\subsection{Models preparation and testing methods}

\subsubsection{Preparation and exposure of mortar specimens}

Mono-material mortar specimens were obtained by pouring the fresh mixtures in polystyrene moulds of $(40 \times 40 \times 160) \mathrm{mm}^{3}$ and by storing them at $\mathrm{RH}=90 \%$ and $T=20 \pm 2{ }^{\circ} \mathrm{C}$ for 28 days, according to the diffuse norm EN 196-1:2005 [31]. Later, they were cut into cubes of $40 \times 40 \times 40 \mathrm{~mm}^{3}$. The maximum compressive strength and a complete microstructure of natural hydraulic lime and the Pozzolana-lime mortars is not usually reached within a curing time of 28 days. However, 28 days of hardening, without the use of forced carbonation, were chosen for both the mortar specimens and renders in order to replicate the EN 196-1:2005 [31] conditions. Moreover, when a render is applied on a salt loaded masonry, it will be most likely subjected to salt transport and crystallization in short times, regardless its peculiar curing time or condition.

The exposure of the cubic specimens to a sodium sulphate solution was performed by immersion cycles of two hours in a saturated salt solution of sodium sulphate decahydrate, followed by drying at $40{ }^{\circ} \mathrm{C}$ for $22 \mathrm{~h}$ in a ventilated oven. This method, based on EN 12370 [32], was opted in order to determine the serious and damaging effects of sodium sulphates, due to crystallization pressure or shrinkage in relation to the transformation between the different hydrates or dissolution [33]. The cycles were repeated until the specimens severely deteriorated.

\subsubsection{Physical evaluation of mortar specimens}

Physical evaluation was conducted both before and after the exposure, in order to investigate the evolution of the mono-material mortar mixtures due to exposure. Density and porosity were measured in order to characterize the pore structure of the mortars and its variations with the presence of salt. The bulk density was calculated on dried prismatic specimens considering the mass and geometric volume of the systems, whilst porosimetric analysis with mercury intrusion porosimetry MIP was carried out by using a Pascal 140 and 240 Thermo Nicolet instruments [34] in order to obtain the total open porosity and pore size distribution, highlighting the effects of the salt presence/ crystallization within the mortars. The samples collected after the exposure, were desalinated with deionized water before MIP analysis. Moreover, in order to evaluate physical changes and salt distribution more accurately, SEM observations (by a JEOL JSM 5600 LV with a OXFORD-Link Isis series 300 microanalysis system on metalized samples) and conductivity measurements (with a Metrohm 644 conductimeter) according to Normal 13/83 [35] were performed on samples collected on the surface and at $0.5-1 \mathrm{~cm}$ depth. It should be mentioned that conductivity measures might be influenced also by partial dissolution of calcium compounds. However, in case of relative measures and short measurement times, conductivity gives interesting information about soluble salt presence and location.

The effectiveness of water-repellency was evaluated by determining the capillary water absorption index [36]. The mechanical properties were evaluated with a compression strength test according to EN 12390-3:2009 [37], with a Lonos tenso-test TT200 press (pre-load of $20 \mathrm{~N}$ and a loading rate of $50 \mathrm{~N} / \mathrm{s}$ ). Desalinated specimens were tested after the exposure to salt crystallization cycles.

\subsubsection{Preparation and exposure of brick masonry/ render macro-samples}

Two walls $\left(50 \times 75 \times 25 \mathrm{~cm}^{3}\right)$ were constructed with full bricks and lime-cement grout over a plastic reservoir $\left(65 \times 35 \times 10 \mathrm{~cm}^{3}\right)$ and covered by a layer of lime-cement grout as rough render (less then $1 \mathrm{~cm}$ thick) in order to homogenize the surfaces (Table 1). The plastic reservoirs were filled with a saturated solution of sodium sulphates for a period of 6 months, obtaining walls already contaminated by salts before the mortar application. Subsequently, the walls were left to dry for a further 12 months, providing dry masonries for application of the mortars.

The mixtures, described in Paragraph 2.1, were uniquely applied as $1 \mathrm{~cm}$ thick renders upon the wall's surfaces, previously wetted by pouring tap water over the surfaces just before the mortar application (Fig. 1). The system was then covered by plastic towels and maintained at a relative humidity of $90 \pm 5 \% \mathrm{RH}$ and 
$20 \pm 2{ }^{\circ} \mathrm{C}$ for 28 days. During the curing, the reservoirs were kept empty in order to avoid capillary rise processes. The 28 day curing time without rising damp, does not exactly reflect actual moist masonries, but was chosen in order to replicate the same hardening/curing condition of the prismatic mortar specimens. The reservoirs were then filled with fresh saturated solution of sodium sulphates and the renders were monitored throughout the capillary rise of the salt solution for a further three months, whilst maintaining a fixed level of salt solution.

\subsubsection{Testing methods of brick masonry/render macro-samples}

The masonry/render system was studied after 28 days of render curing and after a 3 month period with a salt solution filled reservoir.

The walls were monitored visually and by thermal imaging, in order to observe the rising damp processes, the presence of salt efflorescences or other visible decay forms [38]. Thermal imaging measurements were carried out using a Flir B400 Infrared Camera, working in the spectral range of $7-13 \mu \mathrm{m}$, with an IR resolution of $320 \times 240$ pixels, thermal sensitivity of $0.05{ }^{\circ} \mathrm{C}$ at $+30^{\circ}$.

In order to evaluate the salt distribution and effects on the masonry/render system, samples collected from the hardened plaster layers were characterized by MIP

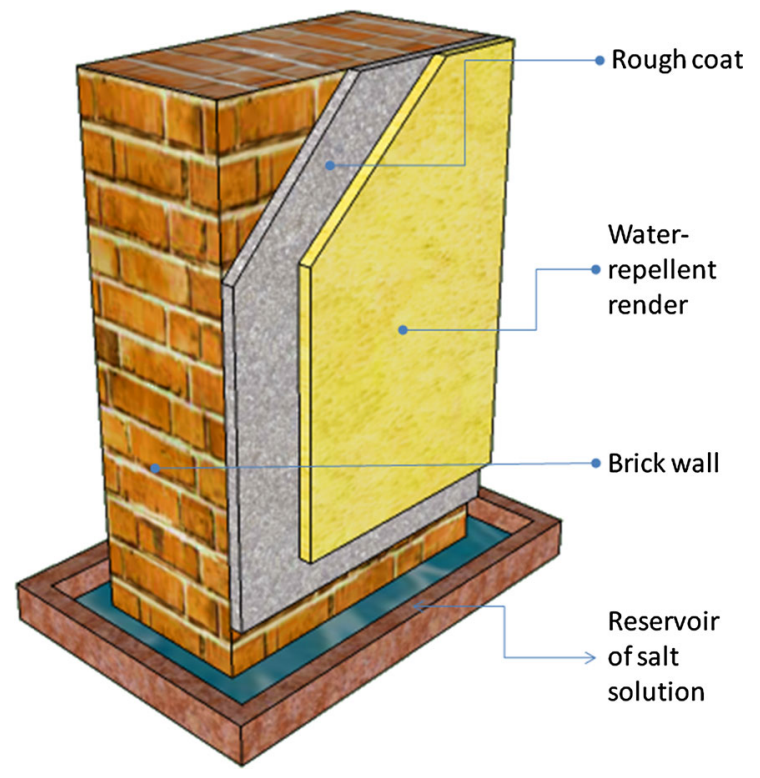

Fig. 1 Model of the wall-render system analyses and measuring their ionic conductivity as explained in Sect. 2.2.2.

In the render case, the determination of the compressive strength by using a press might generate unreliable results, due to their thin thickness (around $1 \mathrm{~cm}$ ), and would result in an invasive analysis. Accordingly, the system's mechanical behaviour was tested by using a Schmidt Hammer PT sclerometer for soft materials (strength between 0.5 and $5 \mathrm{MPa}$, percussion energy: $0.88 \mathrm{~J}$ ) allowing a non-invasive, repeatable determination. The sclerometer rebound is linked to the material hardness and the elastic properties of the renders, furthermore it could be correlated with the compressive strength of concretes. Moreover, this methods has the advantage of identifying weak spots, which often correspond with underlying faults. In order to evaluate the general hydric behaviour of the external surface of the render, water absorption was determined by tube test with a pipe-like apparatus for vertical surfaces [39].

\section{Results on mortar specimens}

\subsection{Physical characterization of mortar specimens before exposure}

The water repellent mortar's physical and structural characteristics after 28 days of hardening are summarized in Tables 2 and 3. Each different mortar mixture was characterized by different pore structures that partially influenced the compressive strength. The low bulk density and the high total open porosity (values around $50 \%$ ) of the NMs' mortars, corresponded to low compressive strength (values around $1 \mathrm{MPa}$ ). The CMs' mortars had low porosity (around $28 \%$ ) and high compressive strength (around 10-15 MPa), whilst the PMs' mortars, with porosity similar to CMs' mortars, demonstrated lower mechanical properties in comparison to CMs' mortars. In fact, the cement based mortars are able to reach a good fraction of their final strength in 28 days of curing, thanks to $\mathrm{C}_{3} \mathrm{~S}$ hydration, whilst NHLs' and PMs' mortars, both having different compositions and curing mechanisms (mainly $\mathrm{C}_{2} \mathrm{~S}$ phases for NMs and pozzolanic reaction for PMs), were not able to reach their final strength at 28 days. However, these two systems do not reach a hardness similar to cement mortar even with long curing times due to a lower production of $\mathrm{C}-\mathrm{S}-\mathrm{H}$ phases [14]. 
Table 2 Properties of hardened mono-material specimens

\begin{tabular}{|c|c|c|c|c|c|c|c|c|}
\hline \multirow[t]{3}{*}{ Sample name } & \multirow{2}{*}{\multicolumn{2}{|c|}{$\frac{\text { Bulk density }}{\mathrm{g} \mathrm{cm}^{-3}}$}} & \multirow{2}{*}{\multicolumn{2}{|c|}{$\frac{\text { Conductivity } 0.5-1.0 \mathrm{~cm} \text { depth }}{\mu \mathrm{cm}^{-1}}$}} & \multirow{2}{*}{\multicolumn{2}{|c|}{$\frac{\text { Capillary water absorption index CI }}{\mathrm{kg} \mathrm{m}^{-2} \mathrm{~h}^{-0.5}}$}} & \multirow{2}{*}{\multicolumn{2}{|c|}{$\frac{\text { Compressive strength } \sigma}{\mathrm{MPa}}$}} \\
\hline & & & & & & & & \\
\hline & Before & After & Before & After & Before & After & Before & After \\
\hline $\mathrm{CM}$ & 1.63 & 1.18 & 70 & 101 & 1.64 & 2.63 & 11.07 & $--^{\mathrm{a}}$ \\
\hline CM750 & 1.65 & 1.65 & 71 & 114 & 0.18 & 0.12 & 8.25 & 4.91 \\
\hline CMcast & 1.73 & 1.29 & 85 & 121 & 0.47 & 1.46 & 14.56 & 3.38 \\
\hline NM & 1.53 & 1.37 & 83 & 101 & 11.90 & 19.95 & 1.32 & 0.12 \\
\hline NM750 & 1.18 & 1.18 & 108 & 114 & 0.24 & 0.45 & 0.89 & 0.30 \\
\hline NMcast & 1.21 & 1.11 & 91 & 137 & 1.01 & 3.63 & 0.62 & 0.12 \\
\hline PM & 1.71 & 1.07 & 71 & 210 & 20.01 & $-^{\mathrm{a}}$ & 2.00 & $--^{\mathrm{a}}$ \\
\hline PM750 & 1.52 & 1.52 & 85 & 81 & 0.05 & 0.07 & 1.07 & 0.71 \\
\hline PMcast & 1.65 & 1.45 & 102 & 235 & 0.25 & 3.64 & 2.01 & 0.37 \\
\hline
\end{tabular}

The error is on the last digit

a The specimens were completely destroyed during the weathering cycles and was not possible to test them

In every case, the use of the siloxane admixture caused a decrease in the compressive strength of the mortars (CM750; NM750; PM750), in comparison to the reference mixtures. In the case of CMcast and PMcast, the presence of calcium stearates increased the compressive strength, whilst with NMcast it decreased dramatically. This behaviour is most likely due to the influence of the water repellent admixtures on the mortar hardening and binder hydration, leading to low quality $\mathrm{C}-\mathrm{S}-\mathrm{H}$ and a weaker structure $[15,40]$.

The samples CM750; NM750; PM750 had low water uptake (Table 2), thanks to the presence of long aliphatic chains within the siloxane product, alongside a good distribution of the product over the open pore walls and external surfaces. The mortars CMcast, NMcast, PMcast also had low water absorption, however slightly higher than that of the siloxanes. This difference could be due to calcium ion exchange mechanisms of calcium stearates with the binder and a subsequent sequestration of the stearates on the binder grains [24]. The absence of water-repellent admixtures resulted in completely wettable and high water absorbing mortars, differing in capillary absorption between $\mathrm{CM}, \mathrm{NM}$ and PM mainly due to open pore structure.

\subsection{Behaviour of mortar specimens exposed} to cycles of salt crystallization and location of salts within mortar specimens

The testing of resistance to salt crystallization demonstrated that the specimens behave in very different ways (Fig. 2); the Portland limestone cement mortars showed a good resistance up to 10 cycles, whilst the natural hydraulic lime mortars were destroyed after 4 cycles and Pozzolana-lime mortars after 5 cycles. Additionally, three different trends were observed throughout the cycles (Fig. 2 and conductivity values in Table 2):

- CM, NM, NMcast and PM showed a disaggregation of the external layers, with no thick salt crusts. Porous, coarse and brittle surfaces were detected. The conductivity indicated a deep penetration of the sulphate solution within the structure. The consequent deterioration due to salt crystallization-dissolution cycles, caused continuous loss of the external salty parts, thus preventing salt crusts formation.

- CMcast and PMcast underwent serious mass losses, with detachment of the external layer, cracks and disaggregation of the internal matrix. The formation of sodium sulphate crusts at the interfaces brick-renders and within the rough render (conductivity values till $200-250 \mu \mathrm{S} / \mathrm{cm}$ ) caused sub-efflorescences, spalling and bodily detachment of the external layers.

- CM750, NM750, PM750 were almost unaffected by the exposure, the surfaces were partially covered by elongated prismatic crystals of sodium sulphate, but they did not show a dramatic increase in the bulk conductivity: their low capillary water absorption prevented the penetration of salt solution. 
Table 3 Porosity data of samples collected from mono-material mortars and render layers: total cumulative volume, total open porosity, pore size distribution percentages divided within three ranges $(0.006-0.1 \mu \mathrm{m}, 0.1-1 \mu \mathrm{m}, 1-20 \mu \mathrm{m})$

\begin{tabular}{|c|c|c|c|c|c|c|c|c|c|c|}
\hline \multirow[t]{3}{*}{ Sample name } & \multirow{2}{*}{\multicolumn{2}{|c|}{$\frac{\text { Total cumulative volume MIP }}{\left(\mathrm{mm}^{3} / \mathrm{g}\right)}$}} & \multirow{2}{*}{\multicolumn{2}{|c|}{$\frac{\text { Total open porosity MIP }}{(\%)}$}} & \multicolumn{6}{|c|}{$\%$ Pore size distribution } \\
\hline & & & & & \multicolumn{2}{|c|}{$0.006-0.1 \mu \mathrm{m}$} & \multicolumn{2}{|c|}{$0.1-1 \mu \mathrm{m}$} & \multicolumn{2}{|c|}{$1-20 \mu \mathrm{m}$} \\
\hline & Before & After & Before & After & Before & After & Before & After & Before & After \\
\hline \multicolumn{11}{|c|}{ Mortar specimens } \\
\hline $\mathrm{CM}$ & 167 & 200 & 30 & 41 & 32 & 24 & 37 & 32 & 31 & 43 \\
\hline CM750 & 162 & 180 & 29 & 37 & 33 & 25 & 45 & 50 & 22 & 25 \\
\hline CMcast & 149 & 160 & 29 & 31 & 40 & 36 & 47 & 52 & 13 & 12 \\
\hline NM & 340 & 280 & 42 & 44 & 13 & 16 & 25 & 26 & 62 & 58 \\
\hline NM750 & 450 & 430 & 50 & 53 & 12 & 11 & 25 & 23 & 64 & 67 \\
\hline NMcast & 410 & 420 & 53 & 52 & 11 & 8 & 29 & 31 & 60 & 61 \\
\hline PM & 133 & 140 & 25 & 29 & 19 & 16 & 46 & 27 & 35 & 57 \\
\hline PM750 & 214 & 170 & 36 & 29 & 26 & 21 & 39 & 39 & 35 & 39 \\
\hline PMcast & 128 & 140 & 25 & 30 & 26 & 27 & 43 & 28 & 31 & 45 \\
\hline \multicolumn{11}{|l|}{ Renders } \\
\hline Brick & 240 & 230 & 55 & 56 & 6 & 6 & 66 & 60 & 28 & 34 \\
\hline Wall render & 130 & 125 & 28 & 30 & 21 & 20 & 25 & 21 & 55 & 58 \\
\hline CR & 154 & 136 & 31 & 32 & 13 & 16 & 21 & 20 & 66 & 64 \\
\hline CR750 & 110 & 107 & 23 & 22 & 23 & 17 & 56 & 46 & 23 & 37 \\
\hline CRcast & 177 & 103 & 33 & 22 & 8 & 15 & 26 & 23 & 65 & 61 \\
\hline NR & 194 & 206 & 36 & 36 & 13 & 13 & 58 & 77 & 28 & 10 \\
\hline NR750 & 218 & 223 & 36 & 40 & 12 & 15 & 29 & 40 & 59 & 45 \\
\hline NRcast & 232 & 237 & 38 & 41 & 16 & 18 & 72 & 72 & 12 & 9 \\
\hline PR & 111 & 97 & 23 & 21 & 21 & 17 & 41 & 41 & 38 & 41 \\
\hline PR750 & 128 & 236 & 26 & 45 & 23 & 7 & 37 & 21 & 40 & 72 \\
\hline PRcast & 137 & 187 & 27 & 38 & 21 & 6 & 24 & 24 & 55 & 70 \\
\hline
\end{tabular}

Samples after desalination were tested

\subsection{Pore distribution of mortar specimens}

The observed pore distribution after the exposure (Table 3) showed the following:

- In CM, PM and PM750, an increase of large pores (10-20 $\mu \mathrm{m}$ range) and decrease of medium and small pores $(0.001-1 \mu \mathrm{m}$ range), due to the enlargement of smaller pores under the pressure of salt crystallization/hydration, perhaps with the formation of larger intercommunicating pores;

- In NM and CMcast, slight decrease of large pores (1-10 $\mu \mathrm{m}$ range), a slight increase of medium pores (0.1-1 $\mu \mathrm{m}$ range) and a decrease of smaller pores, most likely due to enlargement of the thinner pores and a partial pore section reduction of larger pores possibly due to residual salt deposition;

- In NMcast and PMcast, an increase of large and medium pores (0.2-20 $\mu \mathrm{m}$ range), stable distribution of small pores. It is possible that the salty water was able to penetrate the larger pores, thus allowing crystallization/dissolution-hydration shrinkage. Smaller pores remained unchanged thanks to an improved water-repellent effect, due to a higher ratio "surface area/volume of pores" and a stronger repulsive interaction between water and water-repellent surface.

- In NM750 and CM750 pores around $1 \mu \mathrm{m}$ increased slightly after the cycles, since the water was not able to penetrate and transport salts. 


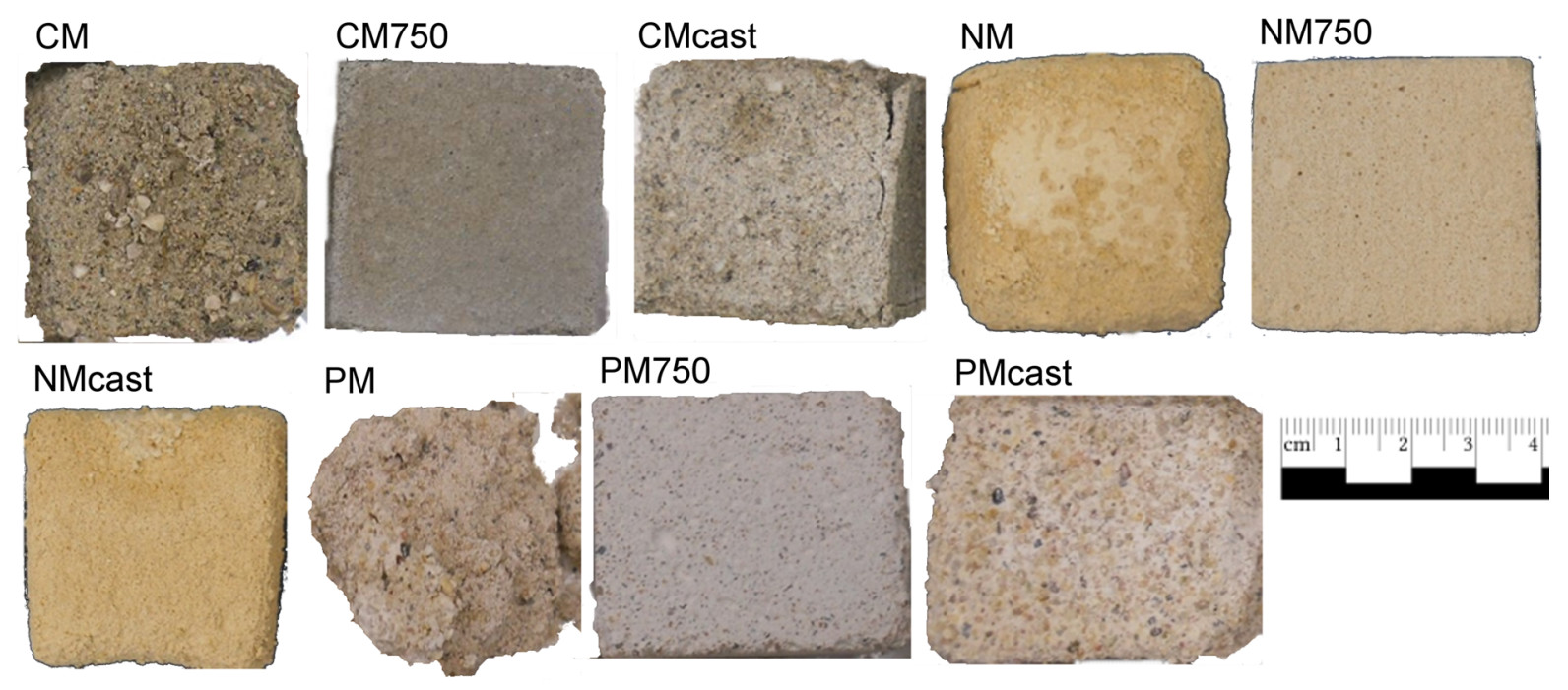

Fig. 2 Mortar specimens after the salt weathering

\subsection{Water repellent behaviour and mechanical properties of mortar specimens}

Following the cycles, the water-repellent properties proved to have been affected too: the water absorption coefficients increased for CM, CMcast, NM, NM750, NMcast and PMcast (Table 2); CM750 and PM750 had lower or similar water absorptions than before; whilst PM absorption coefficient was not measurable due to specimens disaggregation. In the former cases, the partial penetration of salt solution inside the samples and the crystallization of sodium sulphates in depth should have compromised the admixture's water- repellent effect. The salts could increase the porosity and promote water transport deep inside the specimens, by physically covering the pore walls and creating hydrophilic bridges over the water-repellent/ hydrophobic surfaces. Furthermore, the salt hygroscopicity enhanced the water absorption process. In the latter cases, the salt solution was unable to penetrate in depth, but water may have entered as water vapour contributing to a further hydration and compaction of the binder matrix [20,30].

$\mathrm{CM}$ and PM specimens were vastly damaged during the salt cycles. They were brittle to a point that it was not possible to measure the mechanical properties by compressive testing. The data regarding the other mixtures (Table 2) show that the compressive strength decreased after the salt weathering in every case: CM750 and PM750 halve their compressive strength. NM, NM750, NMcast and PMcast diminished the strength even further.

\section{Results regarding brick masonry/render macro- samples}

4.1 Visual and thermal observation of waterrepellent renders on masonries' macrosamples

The renders (R) applied on dry brick walls were monitored before, during and after three months of capillary absorption of salt solution. Figures 3 and 4 shows some of the more representative pictures and thermograms, collected before and after the treatment. IR thermography allows the visualization of temperature changes of the very surface of the material. The surface temperature can be influenced by underlying moisture retention that induce variation in heat conductivity of the material and by water evaporation (lower temperatures are detected in correspondence of moist areas or areas with fast evaporation). Primarily, the renders without admixtures (CR,NR,PR) had smooth and homogeneous surfaces, dry and free from salt efflorescences. After three months of exposure, the thermograms indicated lower temperature on the lower part of CR, NR and PR surfaces (Fig. 3). The lower temperature was due to the capillary rise of salt solution, material wetness and higher water 
Fig. 3 Picture and

Thermograms of the renders applied on wall: a from left to right $\mathrm{CR}, \mathrm{NR}, \mathrm{PR}$ renders before the exposure to capillary rise; $\mathbf{b}$ from left to right $\mathrm{CR}, \mathrm{NR}, \mathrm{PR}$ renders after the exposure to capillary rise (a)

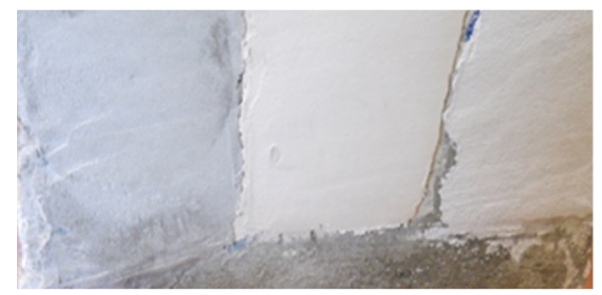

(b)
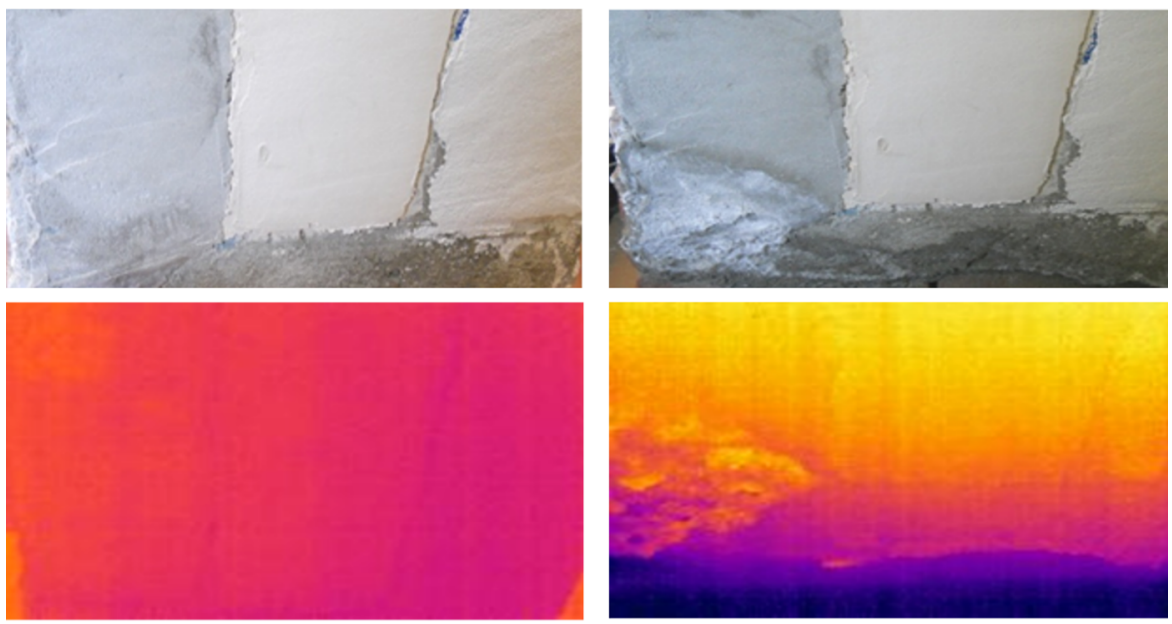

Blue $22^{\circ} \mathrm{C}$
Fig. 4 Picture (a) and Thermograms (b) of the renders Left PR750, right PRcast applied on wall after the exposure to capillary rise of salt solution (a)

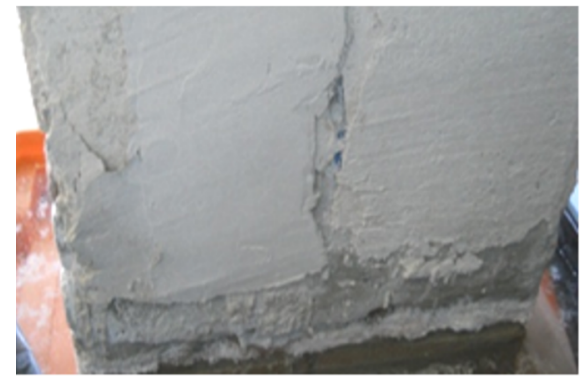

(b)

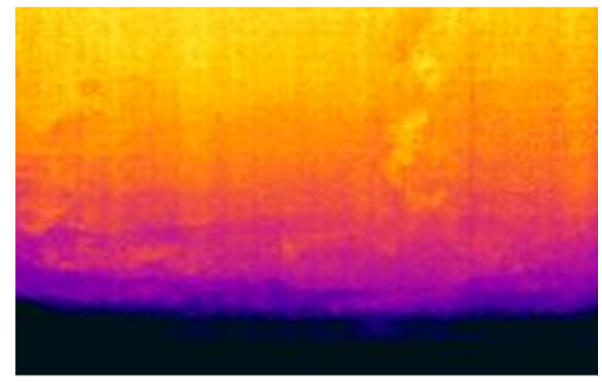

White $26^{\circ} \mathrm{C}$ evaporation from the surface. The mottled parts of the thermograms, in particular near the corners and over the limestone cement CR, corresponded to the presence of salt efflorescences partially visible also by naked-eye observation. CR750 and CRcast seemed free from visible salt efflorescences on the surfaces after the exposure and did not show relevant localized temperature variation. A slight colour gradient of the thermograms indicated quite a homogeneous temperature of the renders surface, with lower temperatures in the lower parts affected by rising damp; but both CR750 and CRcast showed detachments from the walls in different points. NR750 and NRcast showed the presence of salt efflorescences after the exposure and the thermograms were similar to NR. PR750 and PRcast (Fig. 4) had low adhesion to the wall and exfoliation of the surfaces during the exposure occurred, most likely due to salt sub-efflorescences.
The presence of the sub-efflorescences nearby the surfaces was indicated by localized temperature variations in the thermograms of the exfoliated areas where the presence of hygroscopic salts influenced the local temperature by retaining moisture.

\subsection{Salt location within mortar renders and pore distribution on desalinated render specimens}

The conductivity of samples collected from different areas, reflects the salt distribution inside the renders (Table 4). After the exposure, the conductivity increased in the lower areas, which were affected to a greater extent by the capillary rise of salt solution, in particular for CR, PR750 and PRcast (salt efflorescences visible also with naked eye observation). The presence of thick salt crusts was visible within the samples collected from the lower parts of the renders 
CR, CR750, CRcast and NMcast. MIP analysis (Table 3) on desalinated render specimens gives complementary information regarding the effects of salt crystallization within the render structure. Total open porosity variation of the renders occurred only in the lower part of the walls. Before the exposure, the lower parts of CR, CRcast, NR, NR750 and NRcast were characterized by a total open porosity of around $35 \%$, whilst CR750, PRcast, PR750 and PR had open porosity of around $25 \%$. After the exposure, higher total open porosity was detected for NR750, NRcast and PR750, due to the damaging pressure caused by salt crystallization; CR, CR750, PR and NR did not change significantly; CRcast and PRcast demonstrated a decrease in total open porosity most likely due to residual salts deposits or to pore structure failure (chocking of pores lumen). Furthermore, the pore size distribution changed as follow: in NR750 and NRcast it was centred on $1 \mu \mathrm{m}$ before the exposure, after the exposure it broadened and shifted to $0.5 \mu \mathrm{m}$ and $10 \mu \mathrm{m}$; whilst in CR, CRcast and CR750 it shifted from $0.8-1 \mu \mathrm{m}$ to $2 \mu \mathrm{m}$ and $10 \mu \mathrm{m}$, due to enlargement of smaller pores.

\subsection{Water repellent behaviour and mechanical properties of renders applied on brick masonries}

Measurements of the water absorption were performed on the upper, medium and lower part of the wall, evidencing that before the exposure no significant variation could be detected between the different zones. After the exposure, the upper and medium parts, not reached by the rising salt front, did not show significant water-absorption variation in comparison to before. For these reasons, only the absorption degree GA of the lower parts is reported in Table 4.

Before the exposure, the renders CR, PR and NR absorbed more water in comparison to the admixed renders. After the exposure, the lower parts of CR, PR and NR had low absorption, separate from the render porosity or structure: these areas were already moist, due to the capillary rise from the reservoirs and they did not absorb much more water. The water absorption of PR750 and PRcast increased after the exposure. This increase has no relationship with the porosity, but is rather due to water infiltration beneath the renders through little cracks. CRcast and NRcast had higher GA in comparison to CR750 and NR750, both before and after the exposure, and filtration of water was also observed.

Regarding the material hardness, the walls without renders had similar hammer rebounds $\Phi$ in the different areas (around 35-40). The walls covered by CRs' before the salt exposure showed hammer rebounds at around 30 (Table 4). These values decreased after the salt exposure in the lower part of CR750, principally due to the detachments of the render. Natural hydraulic lime renders, before the salt exposure, showed hammer rebounds of around 18-22,

Table 4 Properties of the lower part of the renders before and after the exposure to capillary rise of salt solution

\begin{tabular}{|c|c|c|c|c|c|c|c|c|}
\hline \multirow[t]{3}{*}{ Sample name } & \multirow{2}{*}{\multicolumn{2}{|c|}{ 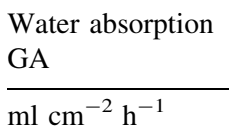 }} & \multirow{2}{*}{\multicolumn{2}{|c|}{$\begin{array}{l}\text { Conductivity } \\
\mu \mathrm{s} / \mathrm{cm}\end{array}$}} & \multicolumn{2}{|c|}{$\begin{array}{l}\text { Hammer rebound } \Phi \text { sclerometer type } \\
\text { PT }\end{array}$} & \multicolumn{2}{|c|}{$\begin{array}{l}\text { Corresponding compressive strength } \\
\sigma^{\mathrm{a}}\end{array}$} \\
\hline & & & & & \multirow[b]{2}{*}{ Before } & \multirow[b]{2}{*}{ After } & \multicolumn{2}{|l|}{$\mathrm{MPa}$} \\
\hline & Before & After & Before & After & & & Before & After \\
\hline $\mathrm{CR}$ & 0.61 & 0.40 & 165 & 727 & 29 & 31 & 2.7 & 3 \\
\hline CR750 & 0.01 & 0.02 & 516 & 576 & 30 & 16 & 2.9 & 1 \\
\hline CRcast & 0.07 & 0.24 & 148 & 180 & 27 & 31 & 2.4 & 3 \\
\hline NR & 0.24 & 0.61 & 76 & 71 & 18 & 17 & 1.2 & 1.1 \\
\hline NR750 & 0.02 & 0.01 & 57 & 882 & 20 & 21 & 1.4 & 1.5 \\
\hline NRcast & 0.46 & 0.20 & 46 & 399 & 22 & 18 & 1.6 & 1.2 \\
\hline PR & 0.37 & 0.54 & 55 & 682 & 33 & 28 & 3.4 & 2.5 \\
\hline PR750 & 0.02 & 0.15 & 74 & 597 & 20 & 9 & 1.4 & 0.4 \\
\hline PRcast & 0.02 & 0.02 & 99 & 95 & 14 & 9 & 0.8 & 0.4 \\
\hline
\end{tabular}

The error is \pm 5 on the last digit

${ }^{\text {a }}$ Calculated according to the conversion curves supplied by the sclerometer instrument producer 
slightly lower for NR. After the salt exposure NR and NR750 remained rather unchanged, whilst the strength of the lower part of NRcast decreased due to salt action. PR750 and PRcast had lower hammer rebounds from the beginning in comparison to $\mathrm{PR}$, most likely as a consequence of a slower hardening of the binder, in the presence of the water repellents. After the exposure, the hammer rebound and the mechanical strength of PR750 and PRcast dramatically dropped, in particular within the lower part of the walls.

\section{Discussion}

\subsection{Mechanism of transport of salty water in the render-masonry system}

The salt solution, transported by rising damp inside the wall and to the wall/render interface, can cross the render in relation to the respective porosity of the layers [23] and to the specific water repellent effectiveness of each mortar mixture.

The renders without admixtures CR, NR and PR were completely wettable. The transport of salt solution through the matrix by capillarity was not inhibited by water-repellent admixtures, but there was no protection against the entrance of external water (e.g. rain). Salt precipitation on or nearby the surfaces occured causing visible moist spots, scaling, and sanding, but was harmless for the conservation of the underlying masonry. In this situation, the transport was mainly driven by the relative porosity of the bricks, the rough wall render and the final renders [22]. $\mathrm{CR}$ and PR acted as quick transporting plasters. In particular, in the CR system, the rough render had pore distribution and total open porosity $\%$ similar to $\mathrm{CR}_{\text {after, }}$ with a smaller average diameter than that of the bricks (Table 3): rapid transport of salts to the layers with smaller pore diameters and to the surface was both expected and observed [22]. However, the low total porosity of CR caused a reduced flow rate, reduced evaporation, and increase of the rising damp level (Table 3). In the PR system, the rough render and PR had similar distribution before the exposure, but the strong accumulation of salt nearby PR surface caused internal de-cohesion, with significant changes in porosity distribution after a few months of exposure.
NR behaved as sacrificial plaster: it's high open porosity and the distribution similar to the bricks caused fast evaporation, receding evaporation front, salt deposition at the interface rough render/NR, in fact few efflorescences where observed. Thanks to its pore structure, NR allow salt storage without severe damage.

In the admixed render systems, the relative water permeability of the different layers was the main driving force for salt transport/deposition, more so than the relative pore distribution. The high waterrepellent effectiveness of CRcast and CR750 may have enhanced the protection of masonries from external meteoric precipitations, preventing water absorption from the outside (low GA), however it slowed down the solution flow towards the surface and caused the formation of salt sub-efflorescences. These mixtures acted as salt blocking plasters: no visible damage was noticed on the surfaces after the exposure, but the adhesion was compromised (as suggested by the sclerometric measurements). Salt precipitation underneath the render and inside the bricks led to degradation of the original masonry, due to the dissolution shrinkage and the crystallization swelling which cause irreversible dilatation of the material [41]. Moreover, the peeling effect due to render detachment could cause further damage.

A blocking behaviour was observed also for the brittle pozzolana-lime renders PR750 and PRcast, but here the combination of low water absorption together with low mechanical strength caused sub-efflorescences, crumbling, and exfoliation of the renders, without direct damage to the masonry. However, the renders' resistance was not enough for their application in a real situation.

NR750 and NRcast did not completely block the solution stream, but they allowed a partial solution transport and the precipitation of the salts both inside and over the render. NR750 and NRcast had the advantage of being constituted of large pores (almost $25 \%$ of the open porosity were pores with radius $\geq 1 \mu \mathrm{m}$ ) able to host a moderate quantity of salts before suffering damages due to crystallization and hygroscopic pressure. Thus, water-repellent natural hydraulic lime renders acted as accumulating plasters. Furthermore, the water absorption was low enough to prevent fast moistening of the wall in case of meteoric precipitation. 
5.2 Properties and behaviour of render-masonry systems in relation to mortar specimens

The results regarding the mortar specimens and renders, together with the render's action mechanism, verify the different behaviour between the mixtures when tested as bulk cubic specimens, in comparison to the render-wall system. These differences are mainly related to: (i) the testing of mono-materials or composite systems; (ii) the exposure mechanism, by immersion cycles or by capillary rise; (iii) the investigative techniques needed for each system.

(i) Regarding the first point, the crystallization test and the characterization of mono-material mortar specimens constitute an important preliminary study of the mixture's behaviour, providing information on the components of more complex wall-render systems (such as structural properties, mechanical properties, etc.). However, such tests did not fulfil the necessity of a wider evaluation of complex systems. In our case, even if more factors influence the results, e.g. the presence of water repellent admixtures influence the water absorption measurements, some conclusion can be drawn on the observed behaviour. In fact, the testing revealed that $\mathrm{CM}$ have a higher resistance to salt crystallization in comparison to PM and NM, due to higher internal cohesion and strength. When waterrepellent agents were admixed, the durability of monomaterial mortars was dependant on: (i) the possibility of the solution entering into the matrix (when the water repellence was high enough, no damages occurred); (ii) the mechanical resistance of the mortar mixture (if the solution was able to enter, the strength and the internal cohesion determined the resistance). In particular, the siloxanes allowed a complete waterrepellence, and good resistance to salt crystallization in every case. The same mortar mixtures, applied as renders on brick masonry, showed a different behaviour and durability: CR, PR, NR allowed the transport of salts and remained adherent to the wall; CR750, CRcast, PM750 and PMcast inhibited the solution transport and delaminated or detached from the bricks; NR750 and NRcast assured protection against the penetration of external water and a sufficient resistance to salt crystallization.

(ii) Regarding the exposure conditions, the immersion cycles of mono-material specimens involves the action of salty solution on each side of the specimen and wetting/drying cycles, leading to cyclic salt precipitation with consequent high stress for permeable materials and strong porosity variation. In this case, the water-repellent behaviour is decisive in determining the material's durability. This exposure is fast, easy to evaluate and repeat. For these reasons, it is frequently used in commercial/industrial evaluation. The "rising damp" exposure allows water and salts to find preferential ways of penetration and crystallization with a continuous flux. It is a slow test, with lower reproducibility, due to the system's complexity, but provides results that are more reliable in view of a site application. In order to counteract the long time required by "rising damp exposure", accelerate experimental conditions were chosen by using saturate sodium sulphate solution and a previous contamination of the wall. These conditions allow to reproduce within few months the decay effects commonly observed in aggressive situations, e.g. in the historical masonries of Venice. In the case of Venice, decay situations similar to the ones obtained in this research have been observed and largely reported [1, 11, 27]. For example, continuous rising damp, contaminated brick masonries and renders (soluble salts up to $20 \%$ ), salt deposition that block pores and enhance moisture level height, renders detachments are observed in the evaporation zone [27].

(iii) Regarding the differences between the investigation techniques, the measurement of similar properties such as the water absorption or the strength have been investigated with different invasive (for monomaterial specimens) or non-invasive (for wall macrosample) methods. A direct comparison is not befitting, however it is possible to observe the presence of similar, comparable trends for the porosity, the absorption behaviour and strength. Moreover, thanks to specific conversion of curves for lime and cement mortars evaluated by the producer of the hammer sclerometer, an indicative correlation between the sclerometer rebound and compressive strength (Mpa) can be done (Table 4).

The porosity data before the exposure, shows that CM, CMcast, PMcast have similar porosity in comparison to the corresponding renders, whilst the others have higher porosity, most probably due to the preparation/application method. After the exposure, the data indicates: i) that CM, CM750 and CMcast increased in porosity due to the exposure cycles, whilst CR, CR750 and CRcast decreased in porosity or remained stable; ii) a similar porosity variation 
occurred for both the natural hydraulic lime mortars and renders; iii) the porosity increased in the pozzolana-lime specimens and decreased in the renders.

The relative comparison of the $\mathrm{CI}$ and GA of mortar specimens and renders demonstrate a comparable trend regarding the water absorption behaviour for the limestone cement specimens or renders: higher water absorption for $\mathrm{CM}$ and $\mathrm{CR}$ in comparison to the admixed ones (the lower absorption measured for $\mathrm{CR}_{\mathrm{after}}$ is due to the mortar wetness, as described in Sect. 3.4); low and similar for CM750 and CR750; increased values for $\mathrm{CMcast}_{\text {after }}$ and $\mathrm{CRcast}_{\mathrm{after}}$. A different relative trend can be noticed for natural hydraulic lime and pozzolana renders or specimens, with the exception of NR- NM. The differences depends most likely both on the different porosity and on the wall dampness after the exposure (Sect. 3.4).

Before the exposure, comparable values of compressive strength were found for the renders in comparison to the mono-material specimens, except for the lower values of CR, CR750 and CRcast, due to the render thickness and the low adhesion to the wall (Tables 2, 4). After the exposure, a significant decrease was observed only for CR750 (bodily detachment), PRcast and PR750 (complete disaggregation and crumbling) in comparison to the mortar specimens, which underwent a serious decrease of their mechanical properties.

\section{Conclusions}

The results underline that the study of the resistance to salt crystallization on mono-material mortar specimens alone, cannot give sufficient data in order to evaluate the suitability of the mortars as renders in both complex and realistic situations. The necessity to develop tests with composite models was a subject addressed by Wijffels and Lubelli [42], Delgado Rodriguez and Verges-Belmin [43], Diaz Gonçalves [20], and Lubelli and de Rooij [44] with absorption/ drying cycles of small brick-render systems. Fundamental information regarding the drying of moist and salt loaded specimens was also collected [20, 22, 23, 45]. However, there still lacks a widespread protocol regarding entire wall/render systems. Small samples do not easily represent well the wall evaporation zone, with the continuous incoming of fresh salty solution due to rising damp.
Mortars and their water-repellence should be calibrated in order to allow a good protection from external water, however avoiding the formation of salt sub-efflorescences. The circulation of water inside the system and the porosity of the materials are both important aspects that have been taken into account throughout this study, in order to find a suitable mortar mixture capable of protecting the walls from the external water and from capillary rise of salt solutions.

The diagnostic methodology proposed, including the study of wall-render systems with non-destructive or micro destructive techniques, has allowed the collection of sufficient data to comprehend the system's behaviour by maintaining a fully-respected and compatible approach, in regards to the wall conservation. This is something that can be further applied in real case studies. Furthermore, the economical sustainability of the test, its reproducibility, and its reliability have all been considered, having tested several mixtures in brief testing times with both different and known compositions. However, the times cannot be shorten too much when using natural hydraulic lime and pozzolana-lime render that needs longer curing times in comparison to cement renders. In this sense future research could take into account the use of parallel samples of natural hydraulic lime and the pozzolan-lime cured for longer times to compare their behaviour. Exploring longer exposure times for the rising damp is one approach to furthering this study, on the other hand, another approach would also be to carry out a real case study with the most promising renders, in order to evaluate their protection against meteoric precipitation and rising damp of salt solution in situ.

Acknowledgments The Authors acknowledge Italian Ministery of Education MIUR for funding the doctorate grant "Study of water repellent system for the preservation and restoration of artificial stone materials". The authors want to thank Jade Straker for her linguistic support.

\section{References}

1. Bakolas A, Biscontin G, Moropoulou A, Zendri E (1996) Salt impact on brickwork along the canals of venice. Mater Struct 29:47-55

2. Benavente D, Garcia del Cura MA, Garcia-Guinea J, Sanchez- Moral S, Ordònez S (2004) Role of pore structure in salt crystallization in unsaturated porous stone. J Cryst Growth 260(2004):532-544 
3. Charola AE (2000) Salts in the deterioration of porous materials: an overview. J Am Inst Conserv 39:327-343

4. Foraboschi P, Vanin A (2014) Experimental investigation on bricks from historical Venetian buildings subjected to moisture and salt crystallization. Eng Fail Anal 45:185-203

5. Scherer GW (2000) Stress from crystallization of salt in pores. In: 9th international congress on deterioration and conservation of stone, Venice, 19-24 June 2000

6. Verhoef LGW (2001) Water-A Paradox, the prerequisite of life but the cause of decay. In: Proceedings of the conference Hydrophobe III surface technology with water repellent agents. Aedificatio Publisher, Zurich, pp 21-36

7. Franzoni E (2014) Rising damp removal from historical masonries: a still open challenge. Constr Build Mater 54:123-136

8. Lanzón M, Garcia Ruiz PA (2008) Effectiveness and durability evaluation of rendering mortars made with metallic soaps and powdered silicone. Constr Build Mater 22:2308-2315

9. Maravelaki-Kalaitzaki P (2007) Hydraulic lime mortars with siloxane for waterproofing historic masonry. Cem Concr Res 37(2):283-290

10. Pavlíková M, Pavlík Z, Keppert M, Černý R (2011) Salt transport and storage parameters of renovation plasters and their possible effects on restored buildings' walls. Constr Build Mater 25:1205-1212

11. Biscontin G, Driussi G (1988) Indagini preliminari sull'azione di intonaci traspiranti su murature umide a Venezia. Recuperare 34:225-229

12. Groot C, van Hees R, Wijffels T (2009) Selection of plasters and renders for salt laden masonry substrates. Constr Build Mater 23(5):1743-1750

13. van Hees R, Naldini S, Lubelli B (2009) The development of MDDS-COMPASS. Compatibility ofplasters with salt loaded substrates. Construction and Building Materials 23 (5):1719-1730

14. Falchi L, Müller U, Fontana P, Izzo FC, Zendri E (2013) Influence and effectiveness of water-repellent admixtures on pozzolana-lime mortars for restoration application. Constr Build Mater 49:272-280

15. Karoglou MA, Bakolas Kouloumbi N, Moropoulou A (2011) Reverse engineering methodology for studying historic buildings coatings: the case study of the Hellenic Parliament neoclassical building. Prog Org Coat 72(1-2):202-209

16. Sabbioni C, Bonazza A, Zappia G (2002) Damage on hydraulic mortars: the Venice Arsenal. J Cult Herit 3(1):83-88

17. Binda L, Baronio G (1987) Mechanisms of masonry decay due to salt crystallization. J Durab Build Mater 4:227-240

18. Binda L, Baronio G (1985) Alteration of the mechanical properties of masonry prisms due to aging. In: McNeilly T, Scrivener JC (eds) Proceedings of the 7th international brick masonry conference, pp 605-616

19. Lubelli B, Van Hees RPJ, Groot CJWP (2006) Sodium chloride crystallization in a "salt transporting" restoration plaster. Cem Concr Res 36(8):1467-1474

20. Diaz Gonçalves T (2007) Salt crystallization in plastered or rendered walls. $\mathrm{PhD}$ Thesis, supervisor Delgado Rodrigues J, Universidade Técnica de Lisboa, Lisbon. http://www-ext.lnec.pt/LNEC/bibliografia/DM/TG_PhDthe sisMar2008.pdf
21. RILEM MS A.1 (1998) Determination of the resistance of wallettes against sulphates and chlorides MS-A.2-Unidirectional salt crystallization test for masonry units. Mater Struct 31:2-19

22. Petković J, Huinink HP, Pel L, Kopinga K, van Hees RPJ (2007) Salt transport in plaster/substrate layers. Mater Struct 40:475-490

23. Petković J, Huinink HP, Pel L, Kopinga K, van Hees RPJ (2010) Moisture and salt transport in three-layer plaster/substrate systems. Constr Build Mater 24:118-127

24. Falchi L, Zendri E, Müller U, Fontana P (2015) The influence of water-repellent admixtures on the behaviour and the effectiveness of Portland limestone cement mortars. Cem Concr Compos 59:107-118

25. Lanas J, Bernal P, Bello MA, Galindo A (2004) Mechanical properties of natural hydraulic lime-based mortars. Cem Concr Res 34(12):2191-2201

26. Binda L, Charola AE, Baronio G (1985) Deterioration of porous materials due to salt crystallization under different thermohygrometric conditions. I Brick. Presses polytechnique romande, Lausanne, pp 279-288

27. Zendri E, Falchi L, Balliana E, Izzo FC, Biscontin G (2014) Impact of climate change on historic architectural surfaces of the Venetian area. In: Proceedings of Società Italiana per le Scienze del Clima, Climate change: scenarios, impacts and policy, pp 991-1003

28. Moropoulou A, Labropoulos KC, Delegou ET, Karoglou M, Bakolas A (2013) Non-destructive techniques as a tool for the protection of built cultural heritage. Constr Build Mater 48:1222-1239

29. EN 197-1:2011 European standard, cement-part 1. Composition, specification and conformity criteria for common cements

30. Falchi L, Varin C, Toscano G, Zendri E (2015) Statistical analysis of the physical properties and durability of waterrepellent mortars made with limestone cement, natural hydraulic lime and pozzolana-lime. Constr Build Mater 78:260-270

31. EN 196-1:2005 Methods of testing cement-part 1: determination of strength. European Committee for Standardization

32. EN 12370 Natural stone test methods-Determination of resistance to salt crystallization

33. Cardell C, Benavente D, Rodríguez-Gordillo J (2008) Weathering of limestone building material by mixed sulfate solutions. Characterization of stone microstructure, reaction products and decay forms. Mater Charact 59(10):13711385. doi:10.1016/j.matchar.2007.12.003

34. UNI Normal $4 / 80$ Italian Normative on stone material. Distribution of pores volume vs their diameter

35. UNI NorMaL 13/83 Italian normative on stone materialdetermination of the content of soluble salts with conductivity measurments

36. EN 1015-18:1999 Methods of test for mortar for masonrypart 18: determination of water absorption coefficient due to capillary action of hardened rendering mortar. European Committee for Standardization

37. EN 12390-3:2009 Testing hardened concrete. Compressive strength of test specimens. European Committee for Standardization

38. Grinzato E, Bressan C, Marinetti S, Bison PG, Bonacina C (2002) Monitoring of the scrovegni chapel by IR 
thermography: giotto at infrared. J Infrared Phys Technol 43(3-5):165-169

39. UNI NorMaL 44/93 Italian normative on stone materialwater absorption at low pressure

40. Li W, Wittman FH, Jiang R, Zhao T, Wolfseher R (2011) Metal soaps for the production of integral water repellent Concrete. In: Borelli E, Fassina V (eds) Proceedings of Hydrophobe VI, 6th international conference on water repellent treatment of building materials. Aedificatio Publisher, Freiburg, pp 145-154

41. Lubelli B, Van Hees RPI, Huinink HP, Groot CJWP (2006) Irreversible dilation of $\mathrm{NaCl}$ contaminated lime-cement mortar due to crystallization cycles. Cem Concr Res 36(4):678-687
42. Wijffels T, Lubelli B (2006) Development of a new accelerated salt crystallization test. Special Issue: COMPASS. Heron J 51(1). http://heronjournal.nl/51-1/2006_1.html

43. Delgado Rodriguez J, Verges-Belmin V (2005) A proposal for classification of salt crystallization behaviour of plasters and renders. EU-COMPASS final report, TNO 2006 D-R0461. COMPASS - compatibility of plasters and renders with salt loaded substrates in historic buildings

44. Lubelli B, de Rooij MR (2009) $\mathrm{NaCl}$ crystallization in restoration plasters. Constr Build Mater 23:1736-1742

45. Diaz Gonçalves T (2010-2013) DRYMASS project drying of porous building materials possibly contaminated with soluble salts. PTDC/ECM/100553/2008. http://www-ext. lnec.pt/drymass/index.html 